\title{
Thermal Influence on the Mechanical Properties of Cardboard during an Ultrasonic-Assisted Embossing Process
}

\author{
Ulrike Käppeler, a,b,* Jennes Hünniger, ${ }^{\text {a,b }}$ André Hofmann, ${ }^{\mathrm{c}}$ Andrea Berlich ${ }^{\mathrm{d}}$ and \\ Lutz Engisch ${ }^{\text {a,b }}$
}

\begin{abstract}
During the embossing process, a fiber sandwich is compressed between embossing tools. The use of ultrasound causes a short-term increase in the material temperature in addition to causing plastic deformation. The combination of the material compression and an increase in material temperature leads to structural changes, which can be observed by the change in mechanical properties of the cardboard. This work investigated the influence of an ultrasonically induced temperature increase on the structural changes of cardboard. Using three-parameter combinations, different temperature levels were achieved with a material densification of less than $5 \%$. Subsequently, the samples were subjected to selected physical and visual analyses to characterize the change in the fiber structure. With the increase of $124{ }^{\circ} \mathrm{C}$ material temperature there was a decrease of about $15 \%$ in the splitting resistance and $10 \%$ in the bending stiffness.
\end{abstract}

Keywords: Heat; Paper; Cardboard; Bending stiffness; Compressibility; Tensile strength; Sample thickness; Visual analysis; Roughness; Mechanical properties; Ultrasound; Embossing

Contact information: a: Leipzig University of Applied Sciences (HTWK Leipzig), Faculty of Computer Science and Media, Karl-Liebknecht-Straße 132, Leipzig 04277 Germany; b: iP $P^{3}$ Leipzig - Institute for Printing, Processing and Packaging Leipzig, Karl-Liebknecht-Straße 132, Leipzig 04277 Germany; c: Technical University of Dresden (TU Dresden), Institute of Natural Materials Technology; d: Leipzig University of Applied Sciences (HTWK Leipzig), Centre for Mathematics and Natural Science, KarlLiebknecht-Straße 132, Leipzig 04277 Germany;

*Corresponding author: ulrike.kaeppeler@htwk-leipzig.de

\section{INTRODUCTION}

Embossings in cardboards are a widely used design element for packages. In addition to improving the optical and haptic effects of the packages, embossing can also have a functional aspect, e.g., the Braille characters for visually impaired users. In a conventional embossing process, the material is compressed between the male and female die. Sometimes heat is used, especially in applications with a hot stamping foil. In addition to conventional embossing methods, ultrasonic-assisted embossing methods have been previously investigated. The use of ultrasonic vibrations during the embossing process allows the material to be compressed $30 \%$ more in comparison to the conventional embossing of cardboard (Hofmann and Hauptmann 2020). Therefore, higher embossing heights can be achieved with less force. A byproduct of the ultrasonic-assisted embossing process is a temperature increase in the center of the material. In the ultrasonic process, the chosen parameters are the primary determinate in the embossing results. The process parameters are the contact pressure, the ultrasound duration, and the value of the amplitude. In terms of increased total temperature, the amplitude has the biggest influence out of the three process parameters (Hauptmann 2017; Löwe et al. 2019). During the embossing 
process the material heats up in the area between the sonotrode and anvil (Radzanowski 2017; Löwe et al. 2019). The temperature increase is caused by intermolecular and interfacial friction, as well as the absorption of the ultrasound energy (Wanske 2010; Radzanowski 2017). However, applying too much heat can lead to scorch markings on the embossing surface (Radzanowski 2017).

Most research activities related to ultrasonic-assisted embossing have dealt with the welding of thermoplastics (Zhang et al. 2010; Neher 2011; Neumann et al. 2016). Loewe et al. (2019) measured the temperature increase in a cross section of cardboard with an infrared camera. Nether (2011) also used an infrared camera but brought into consideration the fact that the temperature was only measured correctly on the focused measuring surface. As a consequence, the resulting measurement uncertainties must be considered. This investigation aims to gather an understanding of whether the short-term temperature increase during an ultrasonic-assisted embossing process influences the material in comparison to a conventional embossing process. There have been some studies on material behavior during increasing temperatures; however, the influence of ultrasound has not been investigated. Back et al. (1966) and Ensminger (2012) showed that the tensile modulus is changed as a consequence of heating up paper. Hauptmann (2017) describes a decrease in tensile strength of cardboard when the temperature increases to greater than $200{ }^{\circ} \mathrm{C}$. Relating to the heat influence on paper, aging processes are often mentioned. Roth (2006) examined the oxidation of paper in relation to the aging process. Paper gets more and more fragile with increasing oxidation. The oxidation process, among other things, is accelerated with an increasing temperature. Wanske (2010) analyzed the results of smoothing paper via ultrasound and describes an embrittlement of the paper and consequently an increase in bending stiffness. For the following experiments of this work, several different ultrasonic parameters were selected, which reached different temperature levels under consideration of a constant material densification. The achieved temperature levels were the basis of the mechanical and visual investigations to gather an understanding of the possible structural changes in the cardboard.

\section{EXPERIMENTAL}

A conventional industrial fresh fiber cardboard Trayforma Natura (Stora Enso, Imatra, Finland) was used. The cardboard has three layers; the outer layers made of sulphate pulp and the inner layer made of chemithermomechanical pulp (CTMP); however, only the central layer contains lignin. As a means of showing the presence of lignin in the middle layer, a cross section of the fiber sandwich was colored with safranin. Deep red color indicates lignin (Fig. 1). Due to softening processes through heating up the samples in the ultrasonic-assisted embossing process, lignin can have an influence on the mechanical properties. Its influence, however, cannot be detected separately with the following experimental setup. The grammage of the cardboard used was $350 \mathrm{~g} / \mathrm{m}^{2}$. Before testing, the material was stored for $24 \mathrm{~h}$ under standard atmospheric conditions $\left(23{ }^{\circ} \mathrm{C}\right.$ and $50 \%$ humidity). After the $24 \mathrm{~h}$ conditioning period, the experiments occurred under the same climatic conditions. The cardboard was cut then into samples with a width of $15 \mathrm{~mm}$ and a length of $150 \mathrm{~mm}$. 
a)

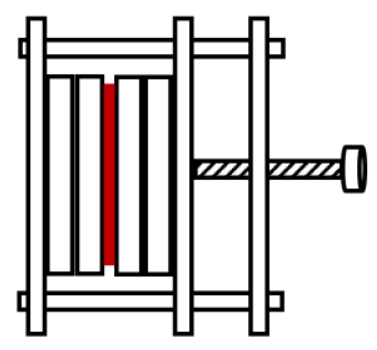

b)

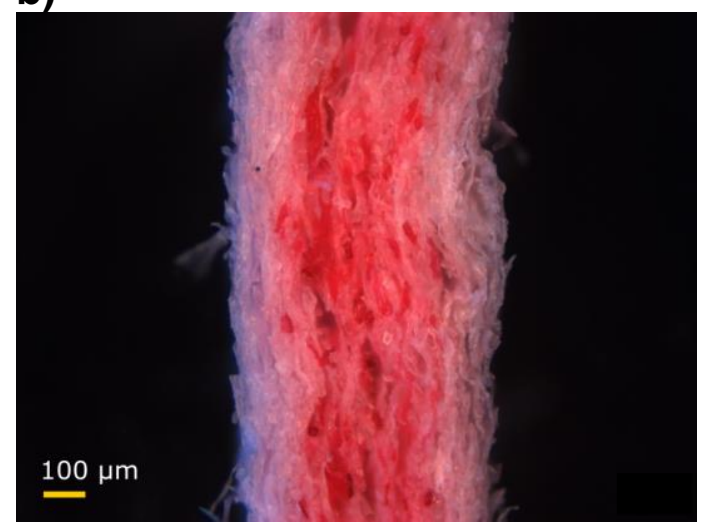

Fig. 1. Hoffmann pinch cock for preparing the cross section of a fiber sandwich (a); colored cross section of the fiber sandwich that demonstrates the presence of lignin in the middle layer (b)

To analyze the influence of ultrasound on the cardboard, samples that were subjected to ultrasonic treatment were prepared; samples without ultrasonic treatment were also made via mechanical compression for comparison. In this experiment a flat embossing pattern was used to prepare the samples. Non-ultrasonic samples were made using a universal materials testing machine (Zug-Druck-Prüfmaschine, ZwickRoell, Ulm, Germany) using a pressure comparable to the ultrasonic treated samples. For the ultrasonic treated cardboard samples, the discontinuous and gap-controlled experimental technique for the ultrasonic-assisted forming of dry paper webs was used, which was developed at TU Dresden (Hofmann and Hauptmann 2020). A special consideration had to be taken for this experimental setup, as the distance between the sonotrode and anvil had to remain the same during the entire embossing process. The size of the gap was set with help of a servomechanical powered connecting rod. During the ultrasonic embossing process, the connecting rod was in a straight position, and the size of the gap could be set from $20 \mu \mathrm{m}$ to $50 \mathrm{~mm}$. Therefore, the pressure on the sample was caused by the size of the gap. This pressure was calculated with the help of force measurements taken with a quartz crystal force sensor (Quarzkristallkraftsensor 9213B, Kistler, Sindelfingen, Germany). After the static pressure was applied to the sample, the ultrasound amplitude was introduced into the material. The sonotrode had a total electrical output of $2300 \mathrm{~W}$ and a maximal vibration amplitude of $35 \mu \mathrm{m}$. For the following experiments, a male die was pressed into the backside plan of the cardboard samples. For the ultrasonic embossing process, first tests with the chosen cardboard and the described experimental setup showed the relation between the process parameters and the resulting temperature in terms of the fiber sandwich properties. The temperature was measured with a thermographic camera (IR 5320, Infratec, Dresden, Germany). The measurement results were comparable to the measurements of Löwe et al. (2019). Based on the findings, the process window was set between $23{ }^{\circ} \mathrm{C}$ and $140{ }^{\circ} \mathrm{C}$. When the temperatures were higher than the upper limit, the cardboard showed burned areas. For determining the tendencies of different temperature influences on the cardboard samples, three parameter combinations, and consequently, three different temperature levels, were chosen. The ultrasound duration was set to $600 \mathrm{~ms}$, the contact pressure was set to $1 \mathrm{MPa}$, and the amplitudes were set to $25 \mu \mathrm{m}, 31 \mu \mathrm{m}$, and $37 \mu \mathrm{m}$. Table 1 showed the different ultrasound parameters and their related temperatures. 
Table 1. Experimental Settings of the Parameters Pressure and Amplitude in the Ultrasonic-Assisted Embossing Process and the Resulting Temperatures in the Fiber Sandwich

\begin{tabular}{|c|c|c|c|}
\hline \multirow{2}{*}{ Settings } & \multicolumn{3}{|c|}{ Levels } \\
\cline { 2 - 4 } & $\mathrm{T} 1$ & $\mathrm{~T} 2$ & $\mathrm{~T} 3$ \\
\hline Pressure $(\mathrm{MPa})$ & 1 & 1 & 37 \\
\hline Amplitude $(\mu \mathrm{m})$ & 25 & 31 & 124 \\
\hline Measured Temperature $\left({ }^{\circ} \mathrm{C}\right)$ & 68 & 95 & 3 \\
\hline $\begin{array}{c}\text { Confidence Interval with } p \text {-value } \\
0.975\left({ }^{\circ} \mathrm{C}\right)\end{array}$ & 2 & 2 & 3 \\
\hline
\end{tabular}

The experimental setup is shown in Fig. 2. The cardboard was placed between the sonotrode and the anvil. Through the sonotrode, the ultrasound was introduced into the material.

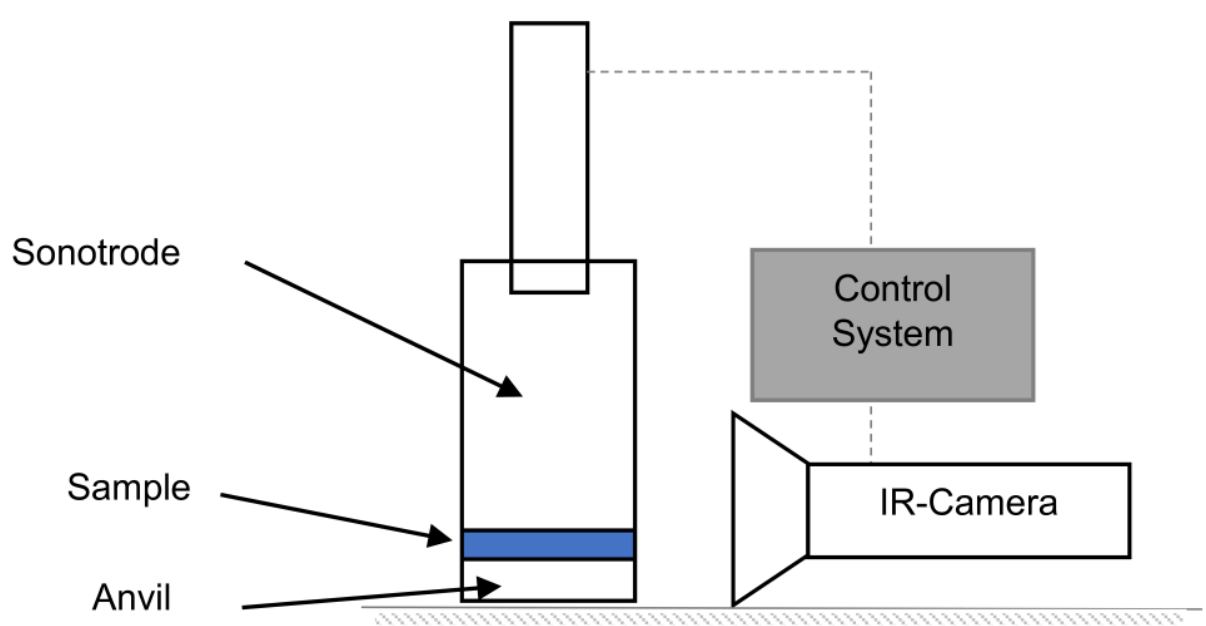

Fig. 2. Experimental setup of the ultrasonic-assisted embossing device

Different mechanical analyses should provide insight into the structural changes in the material. To ensure statistical certainty, 10 samples were each analyzed with the equipment for various measurements, as described in the proceeding sections.

\section{Bending Stiffness}

The samples were positioned on two blocks without being locked. The distance between the two blocks was $50 \mathrm{~mm}$. In the middle of the two blocks, a stamp was pressed against the sample. The force was measured by bending the sample a certain distance with a universal materials testing machine (Universal Zug-Druck-Prüfmaschine, ZwickRoell, Ulm, Germany). The measurements were carried out in machine direction (MD). The material testing followed DIN standard 53121 (2014).

\section{Compressibility}

A circular stamp (10 mm in diameter) was pressed into the cardboard. Force and distance were measured with a universal materials testing machine (Universal Zug-DruckPrüfmaschine, ZwickRoell, Ulm, Germany). The distance was measured optically with two measurement marks (Video Extension, ZwickRoell, Ulm, Germany). For the compression 
test no official standard exists. The experimental setup was newly developed for getting reproducible measurement results.

\section{Splitting Strength}

The samples were fixed with adhesive tape between two chunks of metal. The size of each chunk was $30 \mathrm{~mm}$ to $30 \mathrm{~mm}$. The size of the sample was caused by its geometry and was set on $15 \mathrm{~mm}$ to $30 \mathrm{~mm}$. The chunks were pressed and then divided, beginning on the lower edge. The force that was needed to split up the fiber sandwich was measured using a plybond resistance measurement device (Spaltkraftprüfer, Kögel, Leipzig, Germany). The test followed DIN standard 54516 (2004).

\section{Tensile Strength}

The samples were fixed between two clamps, with a distance between them of $40 \mathrm{~mm}$. The distance between the clamps, i.e, the tensile force, was increased until the sample broke. The maximal force and the elongation was measured with a universal materials testing machine (Universal Zug-DruckPrüfmaschine, ZwickRoell, Ulm, Germany). The measurements were carried out in MD. The test was based on DIN EN ISO standard 1924-2 (2009).

\section{Sample Thickness}

The sample thickness was measured following DIN EN ISO standard 534 (2012) with a thickness tester (Frank Dickenmesser, Frank-PTI GmbH, Birkenau, Germany).

\section{Surface Tension}

The measurement process followed DIN standard 55660-6 (2013). In order to measure the surface tension of the samples, the contact angle was determined. Three different test liquids (water, brom- naphthalene, and diiodmethane) were used and the surface tension was calculated according to the standard measurement method of Owens, Wendt, Rabel, and Kaelble (OWRK) following DIN standard 55660-2 (2011).

\section{Roughness}

The roughness was measured optically with a digital 3D-makroskop (Keyence VR3000, Keyence Deutschland $\mathrm{GmbH}$, Neu-Isenburg, Germany). The characteristic values, $R_{\mathrm{a}}, R_{\mathrm{z}}$, and $R_{\mathrm{q}}$ were calculated according to DIN EN ISO standard 4287 (2010).

\section{Visual Analysis}

The surface and the cross section of the samples were visually analyzed. The samples were cut with a razor blade in order to create a cross section without artifacts, which is important for taking good microscopic images. For that, the sample was fixed in a Hoffmann pinch cock between two pieces of sponge rubber (Fig. 1a). Also, the usage of a resin holder was tested. In the preparation the liquid epoxy resin was penetrating into the cardboard. Therefore, this method was not chosen, because the penetrated resin could probably influence the results. In addition, the quality of the cross section was increased by cutting them with the razor blade. Unlike the samples that were fixed in the resin holder, the cross sections showed no artifacts. Using the resin holder led to splits in the cross section and the separation of fibers on the surface of the cross section. The samples were cut across the machine direction. The images were taken via scanning electron microscopy. 


\section{RESULTS AND DISCUSSION}

The measurements obtained from the mechanical analyses of the cardboard samples changed; as the ultrasound amplitude increased, a temperature increase occurred in the fiber sandwich. Therefore, the changes in the measurement results could be caused by the ultrasonic influence. The measurement results are presented in Fig. 3. The detected changes are shown in terms of the change in percent of the temperature levels T1, T2, and T3 in relation to the reference sample without ultrasonic embossing. The statistical analysis was carried out using a two-sided t-test $(p$-value $=0.975)$. In addition for each parameter the single measurement values are shown in the text below.

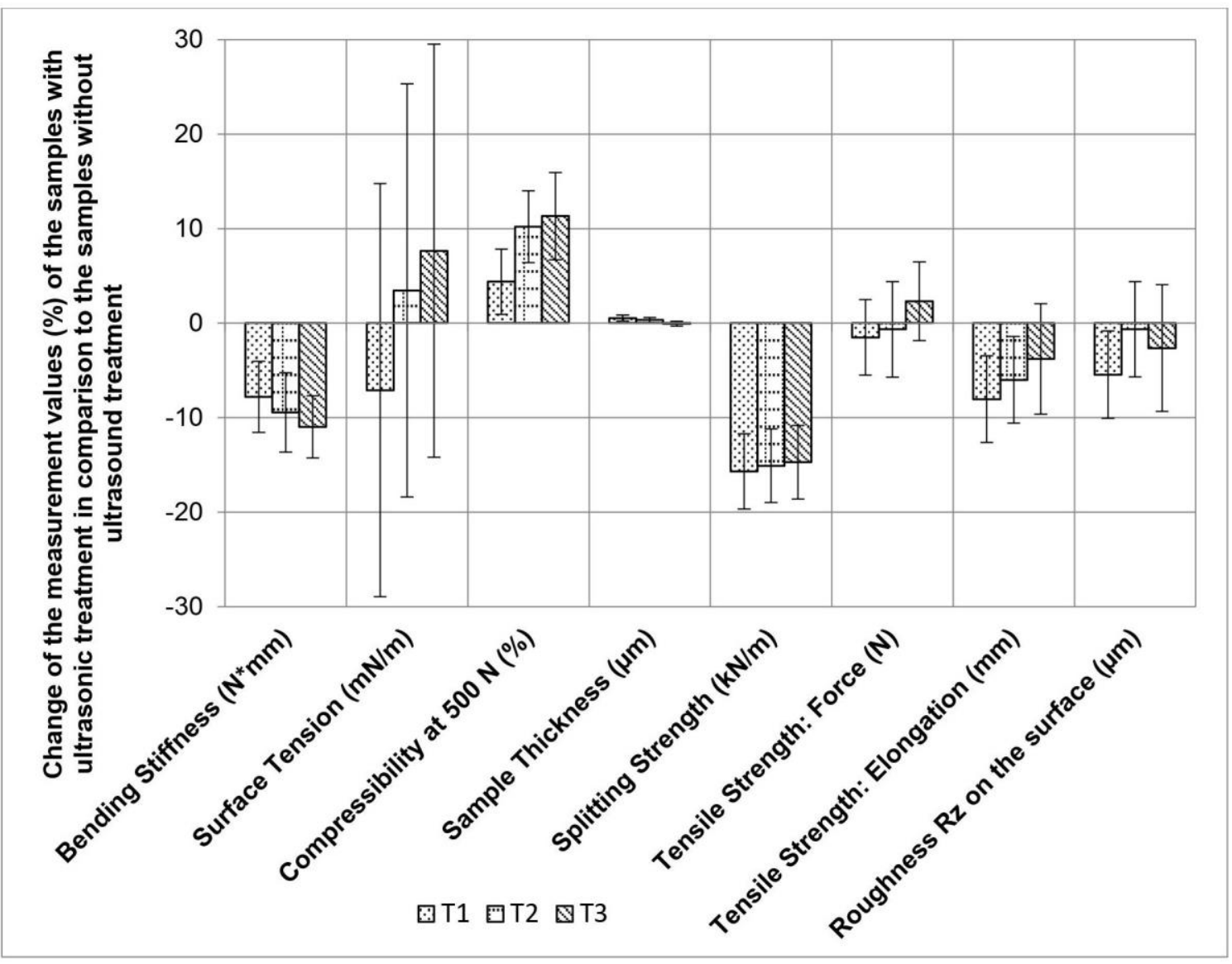

Fig. 3. Change in the measurement values T1, T2 and T3 in percent in comparison to the samples without ultrasonic treatment

\section{Bending Stiffness and Sample Thickness}

The bending stiffness decreased as the ultrasound amplitude and the material temperature increased during the ultrasonic process. The change in the measured value at the highest material temperature (T3) was approximately 10\% lower than the reference sample without an ultrasonic treatment. At the same time, the sample thickness showed no noticeable change. Despite a decrease in material moisture during the ultrasonic treatment (Löwe et al. 2019), there was no increase in the bending stiffness, which was observed by Coffin et al. (2004) in a study regarding cardboard samples of different moisture contents. The measurement results of the bending stiffness showed that an increase in the 
ultrasonically induced material temperature caused a noticeable change in the fiber sandwich. The single measurement values are shown in Fig. 4. As described, the measurement values of the sample thickness were widely spread. Therefore no change of the sample thickness was noticeable.

a)

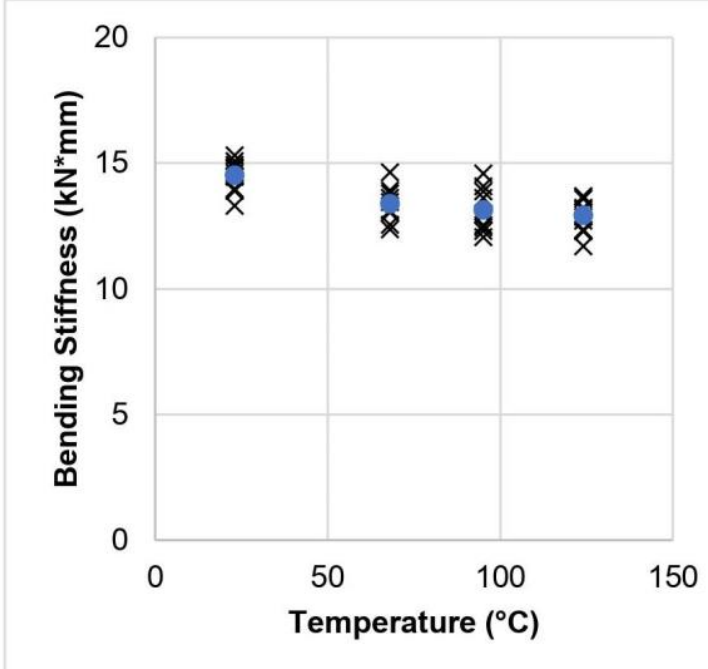

b)

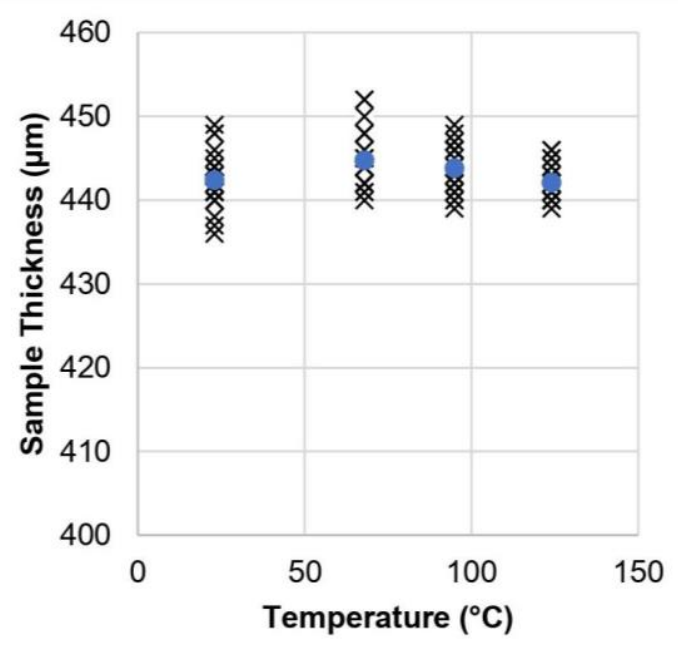

Fig. 4. Single measurement values of the parameters bending stiffness in MD (a) and sample thickness (b).

\section{Compressibility and Splitting Strength}

The results of the compressibility measurement yielded an increase in compression as the material temperature increased during ultrasonic treatment. At the highest temperature level (T3), the compressibility of the cardboard was increased by approximately $10 \%$. This was attributed to the reduction of the material moisture content and the associated fiber shrinkage, which resulted in a loosening of the fiber composite. Consequently, after ultrasonic treatment, the cardboard had a higher compressibility compared to the reference sample. In addition to the change in compressibility, there was also a reduction in splitting strength, as the material temperature increased during the ultrasound process. At the maximum temperature level (T3), a 15\% decrease in splitting strength was observed. The reduction of the splitting strength was based on the induced alternating compressive stresses and the associated delamination phenomena of the individual material layers of the cardboard. The influence on the splitting strength due to the different contribution of thermal expansion among the layers of the fiber sandwich during embossing process seems to be negligible. The position of the split-up in the samples was not noticeably different between the samples of the reference where no heat was applied and the several temperature levels. Therefore, it could be concluded that the different thermal expansion of the introduced heat did not damage mainly one layer and thus the heat expansion had no significant influence on the position where the fiber sandwich splits up. This supported the hypothesis of this study, in which loosening of the fiber sandwich occurred, in addition to the shrinkage of the fibers. The single measurement values of the compressibility and the splitting strength are shown in Fig. 5. The measured values of the splitting strength in particular differed between the measured values of the reference and the three temperature levels. 
a)

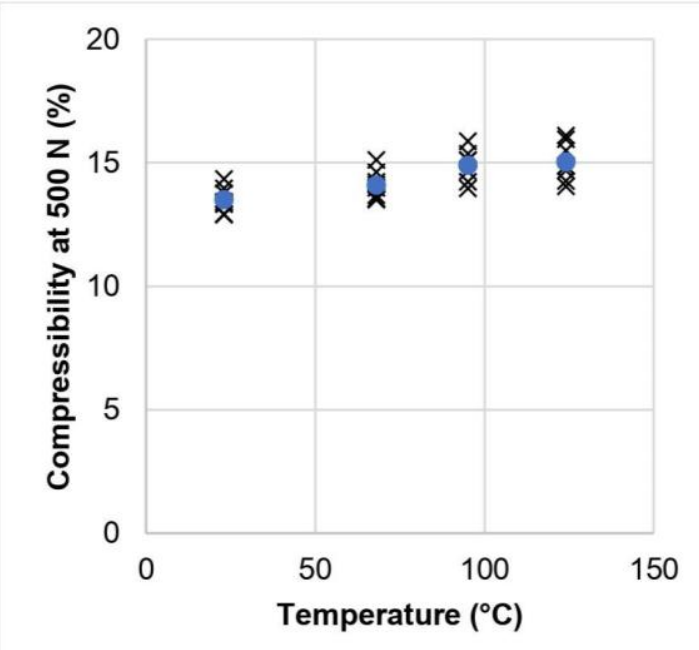

b)

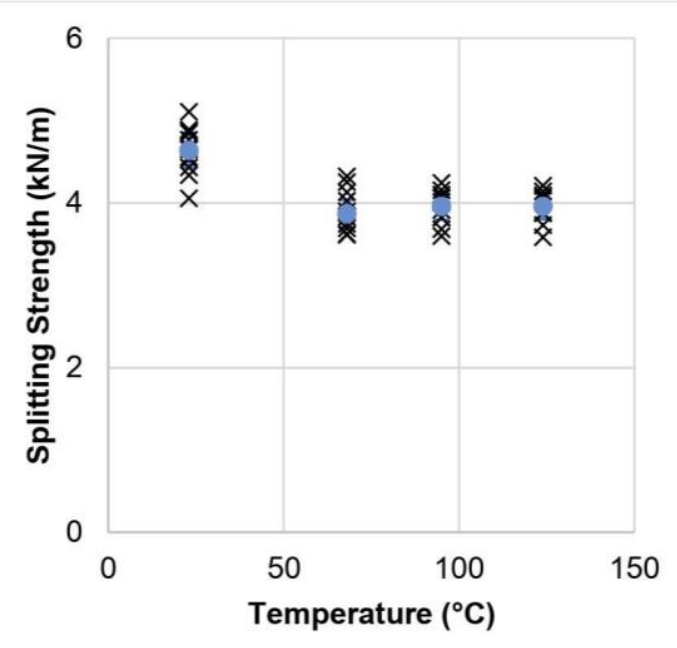

Fig. 5. Single measurement values of the parameters compressibility (a) and splitting strength (b)

\section{Tensile Strength}

The maximal force and the elongation of the samples were measured. The single measurement values of the force and the elongation are shown in Fig. 6.

a)

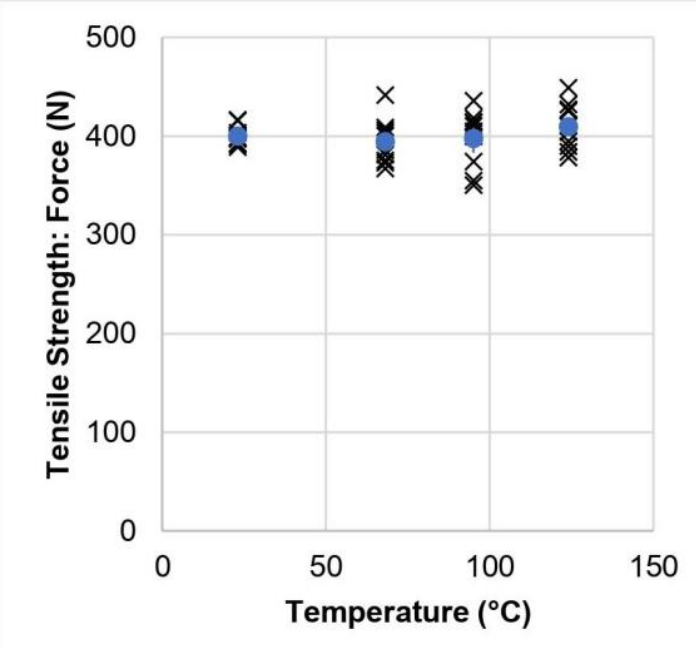

b)

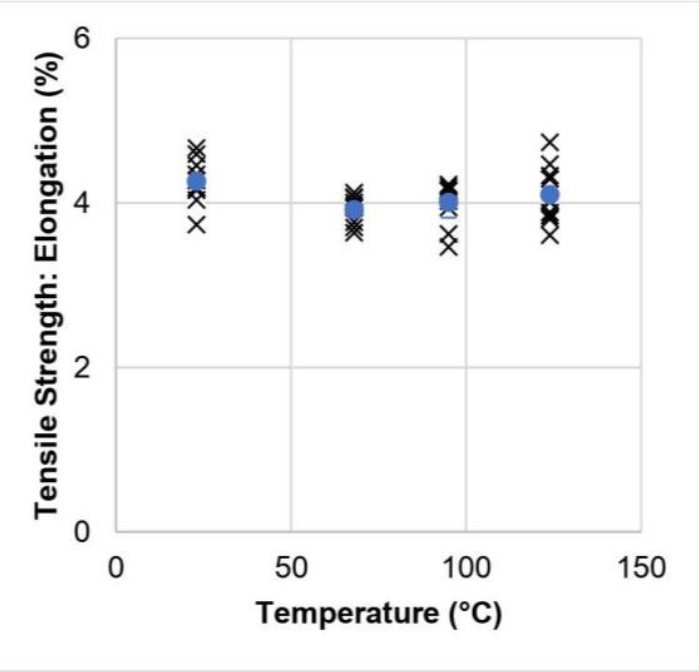

Fig. 6. Single measurement values of the parameter tensile strength, maximal force in MD (a) and elongation in $\mathrm{MD}(\mathrm{b})$

However, the differences between the measurement results are not noticeable, and additionally the measurement values show a large variance (Fig. 3 and Fig. 6). A similarly small impact on the strength potential was also observed by Brenner et al. (2013), who used ultrasonic treatment on the primary fiber materials in the fiber suspension to produce cardboard sheets, which were tested to determine their strength properties. Therefore, the measured values indicated no noticeable influence of the ultrasonically induced 
temperature increase during embossing on the tensile strength and material elongation properties of the cardboard. The almost unchanged measured values of tensile strength indicated that the short-term heating of the material during ultrasonic embossing did not cause an oxidation process, as described by Roth (2006) in the investigations on paper aging. Consequently, the effects of the comparatively slow and continuous heating of the sample were not comparable with the short heating in the ultrasonic-assisted embossing process, where the results of the tensile modulus and tensile strength changed (Back et al. 1966; Ensminger 2012).

\section{Surface Tension and Roughness}

The measurement of the surface tension yielded an increasing trend. However, the examination of the surface tension showed a large variance in the measurement results, which was why this measuring method was considered unsuitable for characterizing the changes in the fiber sandwich. The surface roughness $\left(R_{\mathrm{z}}\right)$ tended to decrease as the process temperature increased during in the ultrasonic-assisted embossing process. Wanske (2010) also achieved a reduction in surface roughness as the material temperature increased. Due to the parallel initiation of vibrations into the cardboard surface, Wanske (2010) achieved higher temperatures on the cardboard surface, which led to a lower roughness value. Since orthogonal vibration initiation was used in this work, the material heated up from the inside to the outside, which led to lower temperatures at the material surface compared to the inside of the material. Based on the obtained results, it was shown that the temperature generated by the ultrasonic waves influenced the surface roughness of the board, whereas the influence of the orthogonal vibration introduction could be neglected when compared to the influence of the parallel vibration introduction. Figure 7 presents the single measurement values of the samples. The measurement values of both parameters showed a large variance.

a)

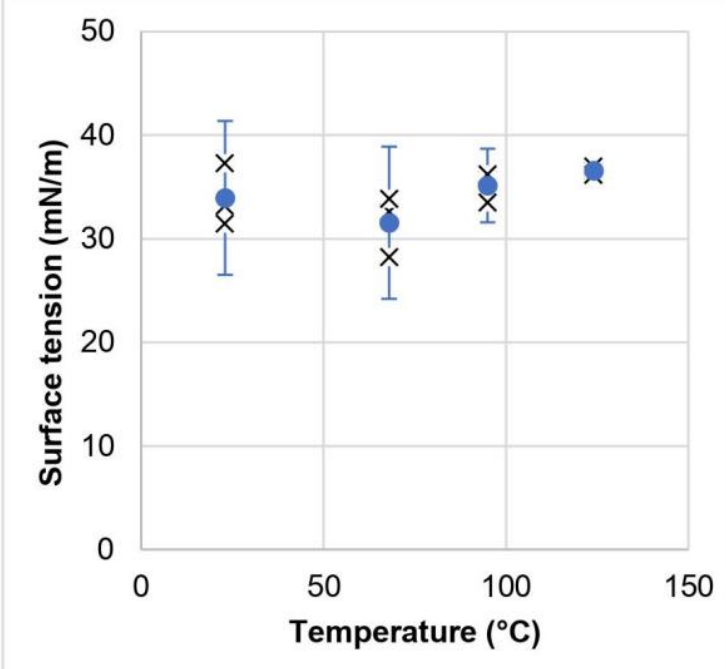

b)

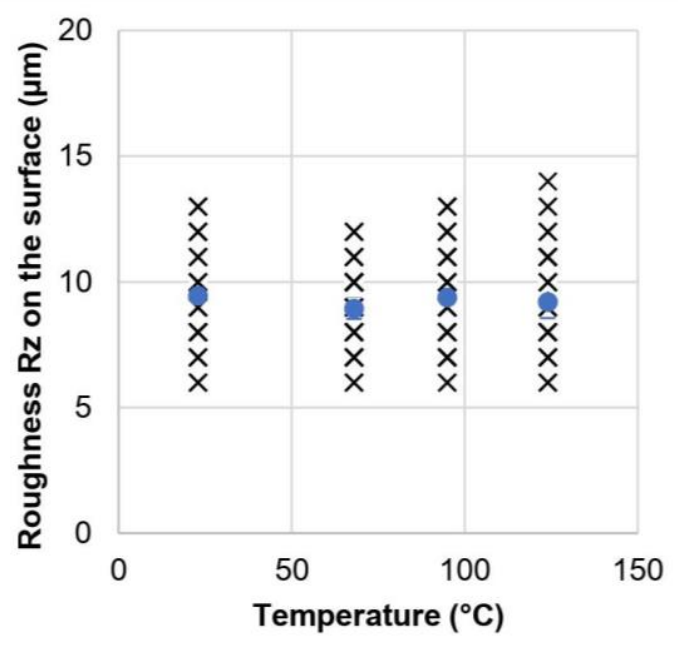

Fig. 7. Single measurement values of the parameters surface tension (a) and roughness $R_{z}$ on the surface of the sample (b) 


\section{Visual Analysis}

Based on the visual analysis of the fiber sandwich (Fig. 8), the hypothesis of this study, in which the loosening of the fiber sandwich was due to the increase in material temperature during the ultrasound treatment, was confirmed. Small hollows between the fibers were visible in the image. Investigations by Loewe et al. (2019) showed that during the ultrasonic-assisted embossing process, water evaporated from the material. The reduction of the material moisture content led to a shrinkage of the individual fibers, which resulted in pores in the fiber sandwich.

The same effects could be assumed in the present investigations. Due to the evaporation of the water in the samples, the fiber sandwich showed holes in the structure. The formation of holes was accompanied by loosening of the fiber sandwich that was assumed on the basis of the measurement results of mechanical properties. The assumption of the fiber loosening was supported by the measurement values, which demonstrated a decrease in bending stiffness and splitting strength. In addition, the increase in compressibility supported this theory. The decrease in bending stiffness meant that it was easier to bend the cardboard, i.e., less force was needed. In addition, the sample was easier to split off in the middle layer, which was shown by decreased bending stiffness values. The increase in compressibility further strengthened the hypothesis, since the same force being exerted against the fiber sandwich yielding further compression. This meant that the cardboard provided less resistance against the force.

a)

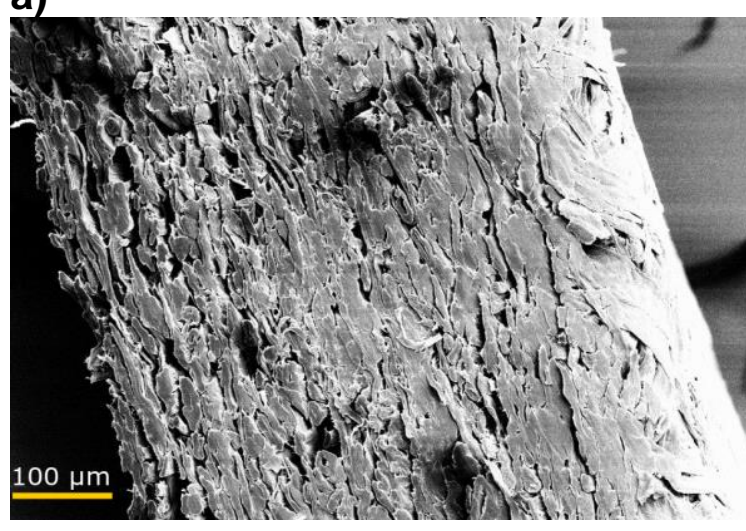

b)

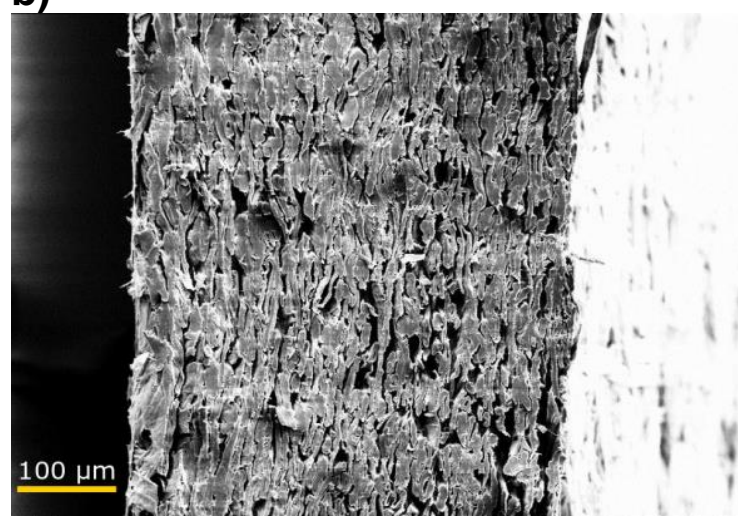

Fig. 8. Cross section of a cardboard sample; sample without ultrasonic-assisted embossing (a) in comparison to a sample with ultrasonic-assisted embossing (b) taken by scanning electron microscope

\section{CONCLUSIONS}

1. The heating of the material during the ultrasonic-assisted embossing process led to a reduction of the material moisture content, which, due to the fiber shrinkage, caused pores and therefore a loosening of the fiber sandwich. The loosening was accompanied by the mechanical measurement results. Beyond the finding of the generation of pores, the precise change in the pore volume due to the ultrasound could not be quantified with the measurement methods used in the work and requires further investigations.

2. The ultrasound-induced material heating reduced the splitting strength compared to untreated cardboard samples. With a temperature of approximately $125^{\circ} \mathrm{C}$ inside the 
material, the splitting strength was reduced by up to $15 \%$.

3. The material heating during the ultrasonic-assisted embossing process led to an increase in the compressibility of the cardboard. With an increase in the material temperature, the compressibility could be increased by up to approximately $10 \%$.

4. Ultrasonically embossed cardboards showed a lower bending stiffness compared to conventionally embossed materials. With an increase in temperature, the bending stiffness was reduced by up to $10 \%$ in comparison to the reference sample without ultrasound.

5. Any changes in the tensile and elongation properties, as well as the surface properties (surface roughness and surface tension), caused by the short-term heating that occurred during ultrasonic-assisted embossing of cardboard were small and therefore did not influence the properties of the fiber sandwich.

\section{REFERENCES CITED}

Back, E., Myat, T., Jackson, M., and Johanson, F. (1966). "The effect of auto crosslinking reactions on the thermal softening of cellulose," Textile Research Journal 37(5), 432-433. DOI: 10.1177/004051756703700514

Brenner, T., Großmann, H., and Arndt, T. P. H. (2013). Ultraschallbehandlung von Naturfasern in der Faserstoffsuspension zur Papierproduktion [Ultrasonic Treatment of Natural Fibers in the Fiber Suspension for Paper Production], München, Germany.

Coffin, D. W., Lif, J. O., and Fellers, C. (2004). "Tensile and ultrasonic stiffness of paper at different moistures," Nordic Pulp \& Paper Research Journal 19(2), 257-263. DOI: 10.3183/npprj-2004-19-02-p257-263

DIN EN ISO 1924-2 (2009). "Paper and board - Determination of tensile properties - Part 2: Constant rate of elongation method (20 mm/min)," Deutsches Institut für Normung [German Institute for Standardisation], Berlin, Germany.

DIN EN ISO 4287 (2010). "Geometrical product specification (GPS) - Surface texture: Profile method - Terms, definitions and surface texture parameters," Deutsches Institut für Normung [German Institute for Standardisation], Berlin, Germany.

DIN EN ISO 534 (2012). "Paper and board - Determination of thickness, density and specific volume," Deutsches Institut für Normung [German Institute for Standardisation], Berlin, Germany.

DIN 53121 (2014). "Testing of paper and board - Determination of the bending stiffness by the beam method," Deutsches Institut für Normung [German Institute for Standardisation], Berlin, Germany.

DIN 54516 (2004). "Testing of paper and board - Determination of plybond resistance," Deutsches Institut für Normung [German Institute for Standardisation], Berlin, Germany.

DIN 55660-2 (2011). "Paints and varnishes - Wettability - Part 2: Determination of the free surface energy of solid surfaces by measuring the contact angle," Deutsches Institut für Normung [German Institute for Standardisation], Berlin, Germany. 
DIN 55660-6 (2013). "Paints and varnishes - Wettability - Part 6: Measurement of the dynamic contact angle," Deutsches Institut für Normung [German Institute for Standardisation], Berlin, Germany.

Ensminger, D. (2012). Ultrasonics: Fundamentals, Technologies, and Applications, $3^{\text {rd }}$ Ed., CRC Press Boca Raton, FL, USA.

Hauptmann, M. (2017). Neue Einsatzpotentiale naturfaserbasierter Materialien in der Konsumgüterproduktion durch die technologische Entwicklung des Ziehverfahrens am Beispiel der Verpackung. [New Potential Applications of Natural Fiber-Based Materials in Consumer Goods Production Through the Technological Development of the Drawing Process Using Packaging as an Example], Postdoctoral Thesis, Technical University of Dresden, Dresden, Germany.

Hofmann, A., and Hauptmann, M. (2020). "Ultrasonic induced material compression during the gap-controlled reshaping of dry paper webs by embossing or deep drawing," BioResources 15(2), 2326-2338.

Löwe, A., Hauptmann, M., Hofmann, A., and Majschak, J.-P. (2019). “Temperature development of cardboard in contact with high-frequency vibrating metal surfaces," BioResources 14(2), 3975-3990. DOI: 10.15376/biores.14.2.3975-3990

Neher, J. (2011). Neuro-Fuzzy Modellierung zur umfassenden Prozessüberwachung am Beispiel des Ultraschallschweißens von Kunststoffteilen [Neuro-fuzzy Modeling for Comprehensive Process Monitoring Using the Example of Ultrasonic Welding of Plastic Parts], Ph.D. Dissertation, University of Stuttgart, Stuttgart, Germany.

Neumann, U., Mitschang, P.,Weimer, C., and Gessler, A. (2016). "Einfluss des Ultraschall Preformens auf die mechanischen Eigenschaften von Kohlenstofffaserverbunden [Influence of Ultrasonic Preforming on the Mechanical Properties of Carbon fiber sandwich]," Zeitschrift Kunststofftechnik/ Journal of Plastics Technology 13(1), 32-36.

Radzanowski, G. (2017). Untersuchungen zu Strukturveränderungen in Karton im ultraschallunterstützten Prägeprozess. [Investigations of Structural Changes in Cardboard in the Ultrasound-Assisted Embossing Process], master thesis, Leipzig University of Applied Sciences, Leipzig, Germany.

Roth, K. (2006). "Chemie kontra Papierzerfall [Chemistry versus paper decay]," Chemie unserer Zeit 40, 54-62, DOI: 10.1002/ciuz.200600376.

Wanske, M. (2010). Hochleistungs-Ultraschallanwendungen in der Papierindustrie Methoden zur volumenschonenden Glättung von Oberflächen. [High-performance Ultrasonic Applications in the Paper Industry: Methods for Volume-saving Smoothing of Surfaces], Ph.D. Dissertation, Technical University of Dresden, Dresden, Germany, ISBN: 978-3-8678-0176-8.

Zhang, Z., Wang, X., Luo, Y., Zhang, Z., and Wang, L. (2010). "Study on heating process of ultrasonic welding for thermoplastics," Journal of Thermoplastic Composite Material 23(5), 647-664. DOI: 10.1177/0892705709356493

Article submitted: February 27, 2020; Peer review completed: April 18, 2020; Revised version received and accepted: May 5, 2020; Published: May 15, 2020.

DOI: $10.15376 /$ biores.15.3.5110-5121 